JOURNAL OF APPLIED CRYSTALLOGRAPHY

ISSN 1600-5767

Received 9 April 2017

Accepted 12 April 2017

Edited by G. Kostorz, ETH Zurich, Switzerland

Keywords: crystal structure synthesis; crystal structure visualization; materials science teaching; educational software.

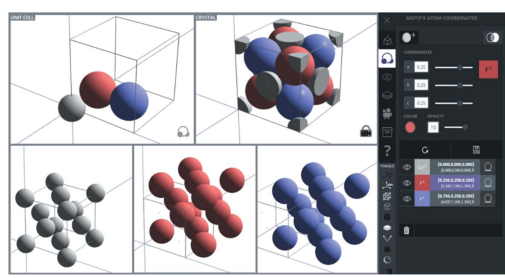

C 2017 International Union of Crystallography

\section{CrystalWalk: crystal structures, step by step}

\author{
Fernando Bardella, ${ }^{*}$ Andre Montes Rodrigues and Ricardo Mendes Leal Neto
}

Center for Materials Science and Technology (CCTM), Nuclear and Energy Research Institute (IPEN-CNEN/SP), 2242

Avendia Professor Lineu Prestes, Sao Paulo, Sao Paulo 05508-000, Brazil. *Correspondence e-mail: bardella@ipen.br

CrystalWalk is a crystal editor and visualization software designed for teaching materials science and engineering. Based on WebGL/HTML5, it provides an accessible and interactive platform to students and teachers by introducing a simplified crystallographic approach that creates crystal structures by combining a lattice with a motif without the use of its internal symmetry. CrystalWalk is the first software to use solely translational symmetry, aiming to introduce engineering students to the basic concepts of lattice and motif. Although very restrictive from the crystallographic point of view, CrystalWalk makes it simple for students to experiment, reproduce and visualize, in an interactive manner, most of the crystal structures that are commonly introduced in materials science and engineering curricula.

\section{Introduction}

CrystalWalk is a crystal editor and visualization software designed for teaching materials science and engineering. Based on WebGL/HTML5, it provides an accessible and interactive platform to students and teachers by introducing a simplified crystallographic approach that creates crystal structures by combining a lattice with a motif without the use of its internal symmetry. Avoiding the concept of space groups and internal symmetry is a didactic strategy often used in engineering textbooks (Van Vlack, 1989; Askeland, 1990; Smith, 1995; Callister \& Rethwisch, 2007), and although elementary from the crystallographic perspective, CrystalWalk is the first software to effectively implement this approach. After choosing a crystal's lattice and entering the atomic coordinates of the translational or complete motif - as described by, for example, Tilley (2006), DeGraef \& McHenry (2007) and Hammond (2009) - unit cells are automatically generated through the rigid sphere model and the lattice and atomic radii data incorporated into the software. Despite being very restrictive from the crystallographic point of view, using solely translational symmetry provides a useful tool to introduce engineering students to the basic concepts of lattice and motif. CrystalWalk makes it simple to experiment, reproduce and visualize, in an interactive manner, most of the crystal structures that are commonly introduced in materials science and engineering curricula.

Fig. 1 illustrates the example of the calcium fluoride $\left(\mathrm{CaF}_{2}\right)$ structure, popularly known as fluorite, a crystal structure where the fluorine sublattice is commonly misunderstood as a simple cubic lattice by students who may lack the skills to properly identify the neighbourhood of the fluorine ion in the representations of most textbooks (Fig. $1 a$ and $1 b$ ). The use of CrystalWalk makes it simple to explore and visualize its threeion motif (one $\mathrm{Ca}$ and two F) and its relationship with the face-centred cubic lattice and sublattices independently for 


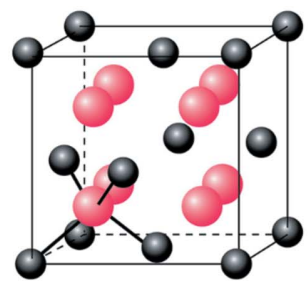

(a)
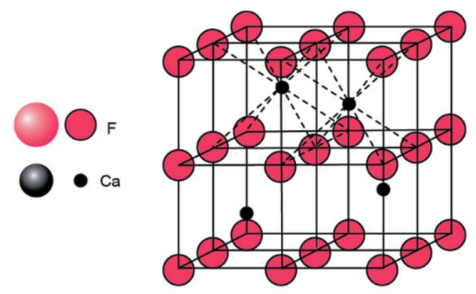

(b)

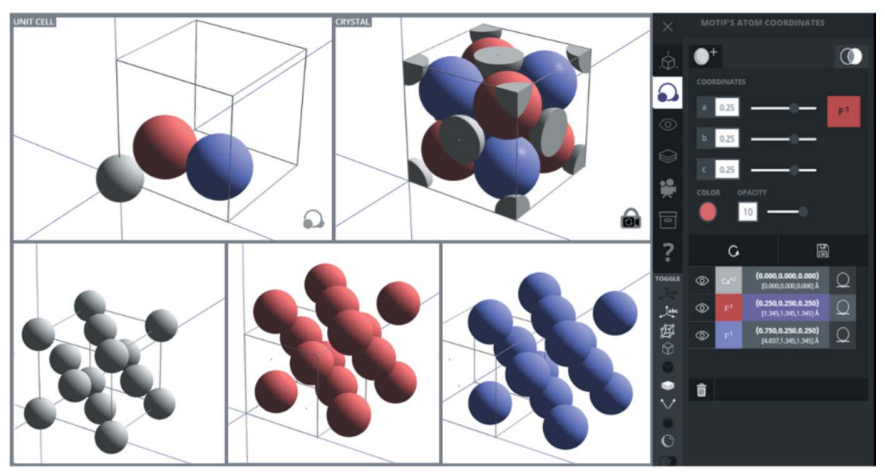

(c)

Figure 1

Unit cell of $\mathrm{CaF}_{2}$ with (a) $\mathrm{Ca}$ atoms positioned externally, at the faces and edges of the cell, and (b) Ca atoms positioned internally. (c) CrystalWalk interface (adapted) displaying the fluorite motif, with the cropped unit cell and sublattices of $\mathrm{Ca}$ (grey) and F (red and blue). Source: (a) adapted from Askeland (1990); (b) adapted from Callister \& Rethwisch (2007).

each member of the motif. This relationship can be easily observed in Fig. 1(c), where each member of the motif has been individually coloured. It is important to highlight CrystalWalk's unique translational symmetry approach, which requires three atoms to define the fluorite motif, while existing crystallographic software uses the minimal asymmetric unit with only two atoms (one $\mathrm{Ca}$ and one $\mathrm{F}$ ).

By consulting powder diffraction files and crystallographic tables it is still possible to use CrystalWalk to create more complex structures by entering individual coordinates from the translational motif. Although this would be laborious and very time consuming for fundamental crystallographic use, exposing students to this task does have its didactic value.
CrystalWalk has a step-by-step tutorial that guides more adventurous users through this process.

Additionally, a comprehensive set of didactic functionalities is available, as an online content publication platform for sharing interactive crystal structures, a 'didactic narratives' tool that enables users to generate interactive classes based on predefined animated sequences as well as providing support for advanced interaction and virtual reality technologies such as Oculus Rift, Google Cardboard, LEAP Motion, multitouch devices and three-dimensional printing technologies.

The development of CrystalWalk was guided by the free software philosophy, adopting state-of-the-art technologies for interactive web applications. CrystalWalk can be accessed online at http://cw.gl from desktop, mobile and tablet devices and its source code is openly available at https:/github.com/ gvcm/CWAPP.

\section{Acknowledgements}

The authors would like to thank all the students, teachers and researchers involved in the project, the Brazilian National Council for Scientific and Technological Development (CNPq), the National Nuclear Energy Commission (CNEN), and the Nuclear and Energy Research Institute (IPEN) for institutional and financial support of this research.

\section{References}

Askeland, D. R. (1990). The Science and Engineering of Materials. London: Chapman and Hall.

Callister, W. D. \& Rethwisch, D. G. (2007). Materials Science and Engineering: an Introduction. New York: Wiley.

DeGraef, M. \& McHenry, M. E. (2007). Structure of Materials. An Introduction to Crystallography, Diffraction, and Symmetry. New York: Cambridge University Press.

Hammond, C. (2009). The Basics of Crystallography and Diffraction. Oxford University Press.

Smith, W. F. (1995). Principles of Materials Science and Engineering. New York: Mcgraw-Hill College.

Tilley, R. J. D. (2006). Crystals and Crystal Structures. Chichester: John Wiley and Sons.

Van Vlack, L. H. (1989). Elements of Materials Science: an Introductory Text for Engineering Students, 6th ed. Reading: Addison-Wesley. 